\section{Risk management in clinical practice. Part 8. Temporomandibular disorders}

\author{
R. Gray ${ }^{1}$ and Z. Al-Ani ${ }^{2}$
}
IN BRIEF
- All patients should routinely be asked about TMD symptoms such as clicks, locking or pain before treatment commences.
- Signs of parafunctional activity should be recorded and an occlusal examination in dynamic and static relationships should be noted.
- Treatment of TMD such as occlusal adjustments are highly contentious and need to be regarded with some caution.

Temporomandibular disorders can arise apparently idiopathically, as a result of macro-trauma or micro-trauma such as parafunction, as a result of a separate disease process or as a consequence of dental treatment. The objectives of this chapter are to make the practitioner aware of his/her responsibilities in any of these situations. Precise record keeping and careful risk management are essential. Guidelines are given to protect not only the practitioner but also the patient.

Dentists might see patients with temporomandibular disorders (TMD), some who are involved in litigation and dentists are not infrequently accused of causing a TMD. Current evidence-based concepts in diagnosis and management must be reflected in clinical practice. To protect him or herself, the clinician should enquire about TMD symptoms before starting dental

\begin{tabular}{l} 
RISK MANAGEMENT \\
IN CLINICAL PRACTICE \\
\hline 1. Introduction \\
2. Getting to 'yes' - the matter of consent \\
3. Crowns and bridges \\
4. Endodontics \\
5. Ethical considerations for dental \\
enhancement procedures \\
6a. Identifying and avoiding medico-legal \\
risks in complete denture prosthetics \\
6b. Identifying and avoiding medico-legal \\
risks in removable dentures \\
7. Dento-legal aspects of orthodontic \\
practice \\
8. Temporomandibular disorders \\
9. Dental implants \\
10. Periodontology \\
11. Oral surgery
\end{tabular}

Former Senior Lecturer, Department of Dental Medicine and Surgery, University Hospital of Manchester : ${ }^{2}$ E-Learning Scientific Development Officer, Glasgow Dental Hospital and School, 378 Sauchiehall Street, Glasgow, G2 3JZ

*Correspondence to: Dr Ziad Al-Ani

Email:z.al-ani@dental.gla.ac.uk

\section{Refereed Paper}

Accepted 20 October 2009

DOI: 10.1038/sj.bdj.2010.981

${ }^{\circledR}$ British Dental Journal 2010; 209: 433-449 treatment and if treating a TMD, stay within accepted guidelines.

\section{DOCUMENTATION AND RECORD KEEPING}

In relation to temporomandibular disorders, it is the duty of the dentist to undertake a thorough examination of the articulatory system at the first and subsequent visits.

It is the responsibility of every practitioner to have an easy to use and failsafe protocol in place. It is not merely sufficient to have a protocol; practitioners are accountable for ensuring that everyone using the protocol does so to its full extent. The signs and symptoms of temporomandibular disorders vary with the stage and progress of the disease and a patient may be suffering from more than one condition. It is therefore essential that good and contemporaneous records are kept, not only of the initial consultation but at subsequent review appointments which may stretch over months or even years.

\section{History}

A careful history should be taken. This should record the patient's first awareness of the symptoms, whether they were of gradual or acute onset and importantly whether there was any initiating event. Trauma is surprisingly rare as an initiating event when one considers how many assaults, sporting and road traffic accidents take place. It is essential for the dentist, however, to record

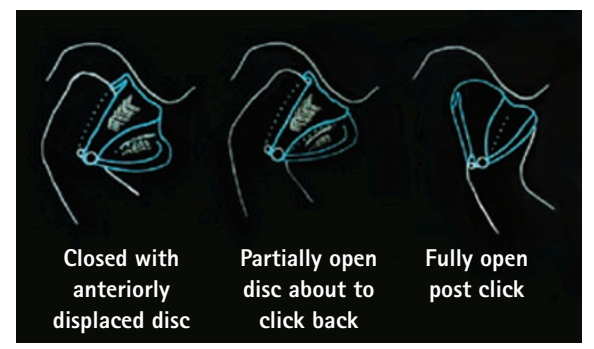

Fig. 1 Disc displacement with reduction (clicking)

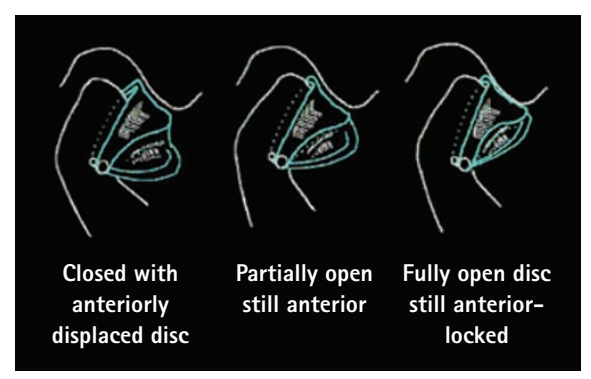

Fig. 2 Disc displacement without reduction (locking)

whether there is any incident involved and to record the subsequent sequence of events.

Often a click can be present for many years only to suddenly disappear and locking to occur. This implies that the patient has had disc displacement with reduction (clicking) (Fig. 1) but the disc displacement had suddenly got to a degree where the diagnosis changed to disc displacement without reduction (locking) (Fig. 2). It is essential for the dentist to recognise this, as treatment for clicking is not only inappropriate for locking but can be positively detrimental. 
In addition to keeping written or computerised records of clinical symptoms and history, other methods of recordkeeping are available. Photography is in widespread use in all aspects of dentistry. When treating TMD patients, intra-oral photographs can be useful in keeping a record of soft tissue signs, such as ridging of the inside of the cheeks and scalloping of the lateral border of the tongue, and in recording tooth surface loss secondary to parafunction. Plaster models of the teeth can be made. If these are to be kept longterm for means of comparison with other models at a later date, they are best cast in die-stone, so they are as hard wearing as possible. It must be remembered, however, that models cannot be regarded as accurate records. There are obvious discrepancies in impression taking depending on, for instance, whether or not special trays are used. It is frequently found that the impression may pull away from the tray in some area rendering inaccuracies in the resultant model. When the models are cast, further inaccuracies can be introduced and if normal dental stone is used the models can abrade and chip readily. Models therefore can only be used for gross comparisons. There are also obvious errors that can be introduced when the models are mounted on an articulator.

It is important, however, for information not only to be recorded but also to be stored and when necessary transferred. A simple and reliable means of recording the results of an examination is important and unless the records are accurate, permanent changes cannot be compared and evaluated. There are therefore three terms to consider:

1. Examination. This is an investigation by inspection

2. Record. This is preservation of the results of an examination and is either two dimensional, for instance a written record, photograph, computer representation or a drawing or sketch, or three dimensional by use of models

3. Registration. This is a physical record by which for instance jaw relationships and upper and lower models can be transferred to an articulator in that jaw relationship.

When considering examination of the occlusion several methods for recording have been reported in the literature. ${ }^{1-4}$ These range from simple techniques using articulating paper or occlusal wax, to more complex instrumental records such as sonography, computerised occlusal contact sensors and pressure sensitive films. Little information is available regarding the reproducibility of these methods and it is accepted that they all have potential drawbacks relating to inaccuracy, problems of manipulation and interpretation.

\section{EXAMINATION}

It is important for the dentist to know what is 'normal'. It is only by knowing this that abnormalities will be detected. The examination should be kept in simple sequence with easy recording methods. This can be done either on computer or by keeping a hard copy of an examination sheet. ${ }^{5-8}$

\section{TMJ examination}

\section{Range of movement}

The range of movement should be measured in the vertical and lateral dimensions (Figs 3 and 4). The method of measuring the range of mandibular movement, for example by use of a ruler, a Willis bite gauge or (most accurately) a Vernier bite gauge, is irrelevant as long as the technique is consistent. It does not matter whether overbite is included or not as long as it is the same every time. It is not adequate to merely record "two fingers width of opening' as this does not provide sufficiently accurate information.

\section{TMJ tenderness}

The temporomandibular joints should be examined for tenderness in several ways, firstly by gentle palpation in the preauricular region. This gives only limited information. The best way of examining the joints for tenderness is by palpation via the external auditory meatus and then asking the patient to gently open and close the mouth (Fig. 5). The disc and capsule of the temporomandibular joint have a poor nerve supply. The posterior bilaminar zone, however, is highly innervated. If there is disc displacement this area inevitably becomes stretched and may become interposed between the head of the condyle and the fossa of the temporal bone. This can lead to painful clicking and indeed

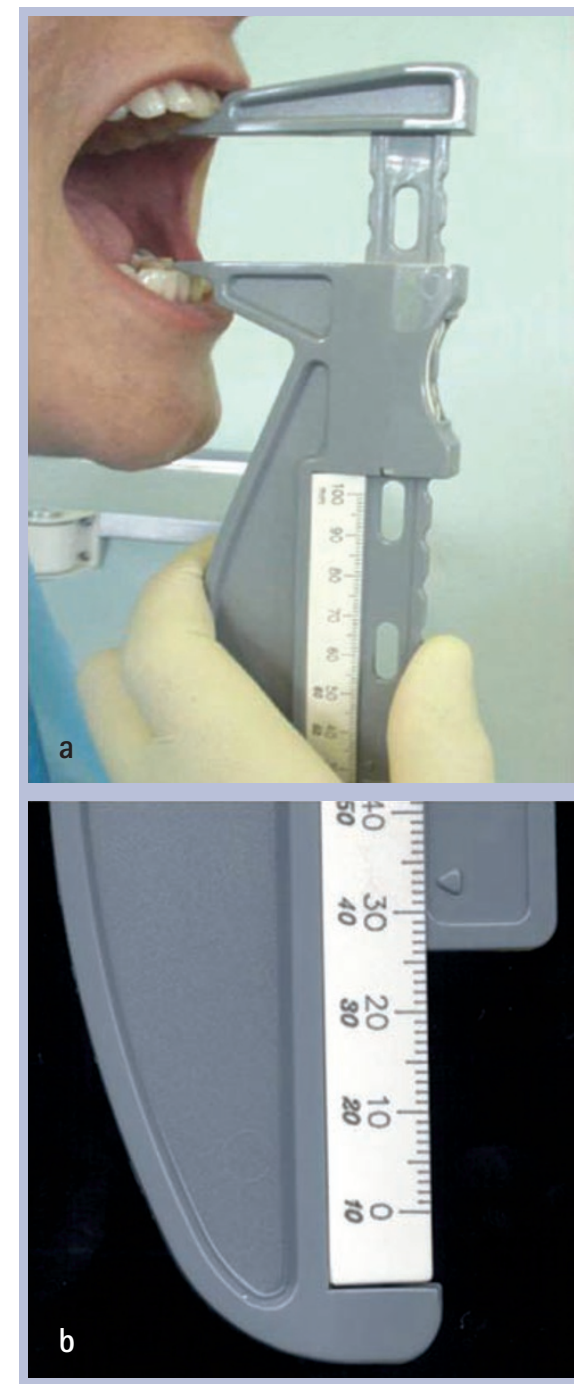

Figs 3a-b Measuring the range of movement in the vertical dimensions

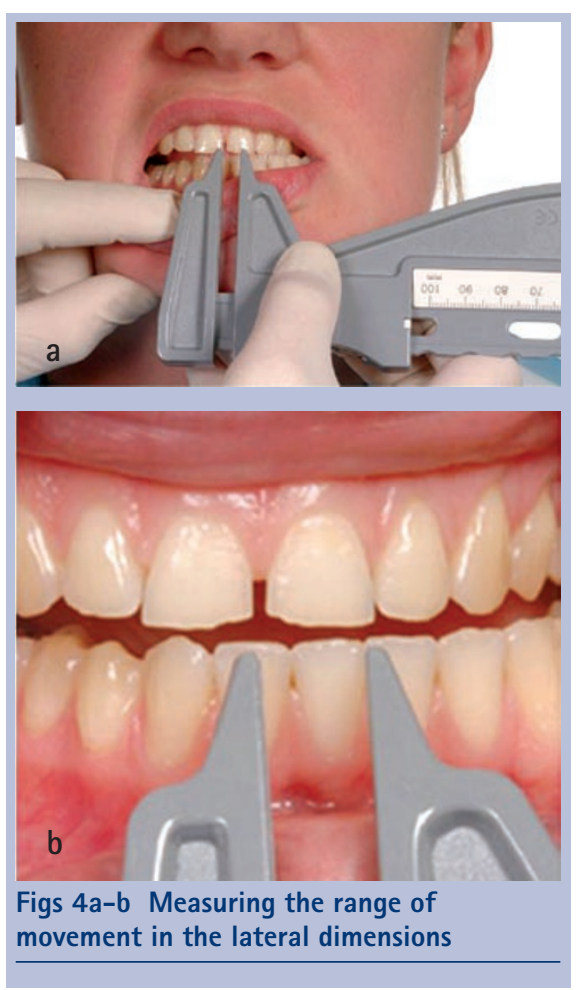




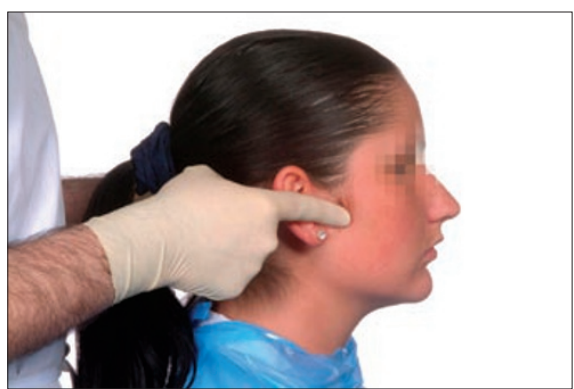

Fig. 5a The joints are examined for tenderness by gentle palpation in the preauricular region

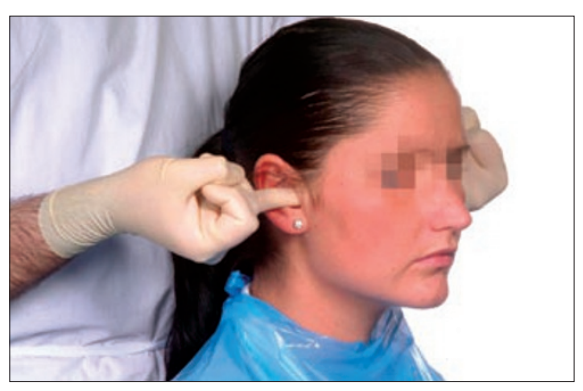

Fig. 5b The best way of examining the joints is by palpation via the external auditory meatus and then asking the patient to gently open and close the mouth

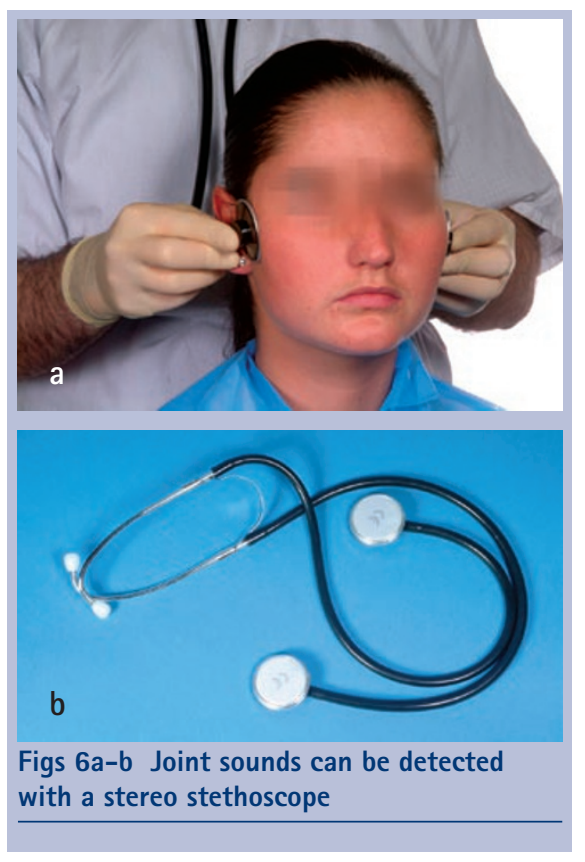

it can be painful for the patient to bite their teeth together. If a patient attends with a complaint of being unable to bring the molar teeth together without sharp shooting pain in the ear, then the dentist should recognise that disc displacement is a possible cause.

The third examination of the joints for tenderness should be gentle manipulation of the mandible to a retruded position. Again if there is disc displacement this will compress the sensitive posterior bilaminar zone and cause discomfort, usually deep within the external auditory meatus.

\section{Joint sounds}

Joint sounds can be detected by palpation but preferably should be detected with a stethoscope, ideally a stereo stethoscope (Fig. 6). Note should be made of whether the click is painful or painless, single or multiple and early or late in the opening/closing cycle. A click varies quite significantly in an individual. If there is a true internal derangement the click is consistently present on opening and closing. If, however, the click is found in a patient with facial arthromyalgia, it may only be present in the morning after the patient has been parafunctioning during sleep due to increased muscle tone in the superior pterygoid muscle. The disc can then partially or completely reposition as the muscle relaxes and the click, which had been present on waking, would subsequently disappear as the day goes on. It is important for the dentist to be aware of this and differentiate between a true internal derangement and a click associated with facial arthromyalgia, as the treatment will vary between the two diagnoses and treatment that might be applicable for one would have little chance of success with the other. The dentist should be aware that patients frequently present stating their 'jaw has dislocated' when what they mean is that it is clicking. True dislocation is very uncommon and the patient would present with an inability to close their mouth and would be in pain.

The other, less commonly encountered joint sound is crepitation. This is usually indicative of degenerative joint disease, such as osteoarthrosis or rheumatoid arthritis. The practitioner should be aware of the fact that rheumatoid arthritis rarely if ever presents in the temporomandibular joint as being the first joint affected and the patient would normally have a preexisting history of rheumatoid arthritis in other joints.

\section{Muscle examination}

The muscles which should comprise part of the examination are the masseter, temporalis and lateral pterygoid. Patients will frequently present with head or facial pain and it is the responsibility of the

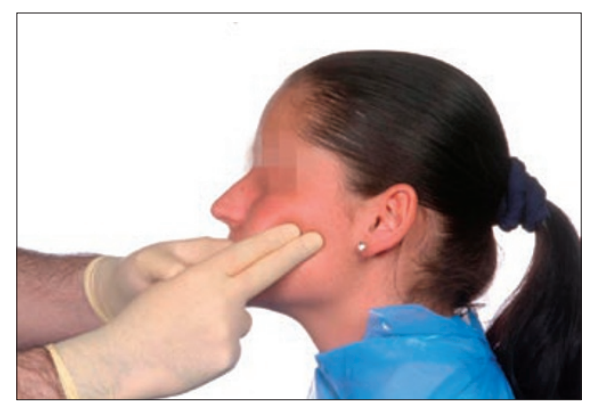

Fig. 7a Masseter origin palpation

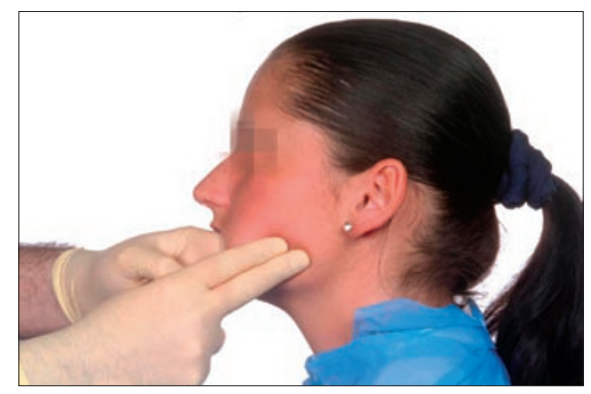

Fig. 7b Masseter insertion palpation

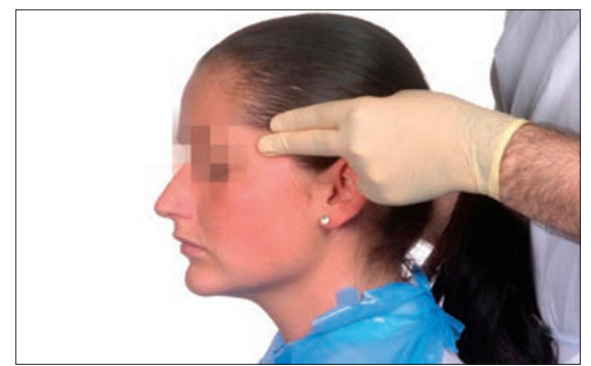

Fig. 8 The temporalis muscle is examined by palpating its origin by asking the patient to clench the teeth together. Digital palpation is performed between the superior and inferior temporal lines just above the ear, extending forwards towards the supra-orbital region

dentist to examine these muscles to illicit whether these are the cause of the pain. These are all small muscles and are usually tender where they insert into bone. The masseter muscle is most often tender in patients who clench their teeth and the usual area of tenderness is either the origin over the anterior two thirds of the zygomatic arch (Fig. 7) or less usually at the insertion over the angle of the mandible. The temporalis muscle is usually tender in the anterior part of the origin in the temple (Fig. 8). This muscle is usually tender in patients who have an active bruxist habit. The anterior fibres are most usually tender as they are the vertical elevator fibres of the mandible.

The lateral pterygoid muscle should be examined against resisted movement (Fig. 9). If there is pterygoid spasm this will produce pre-auricular pain. A dentist 


\section{PRACTICE}
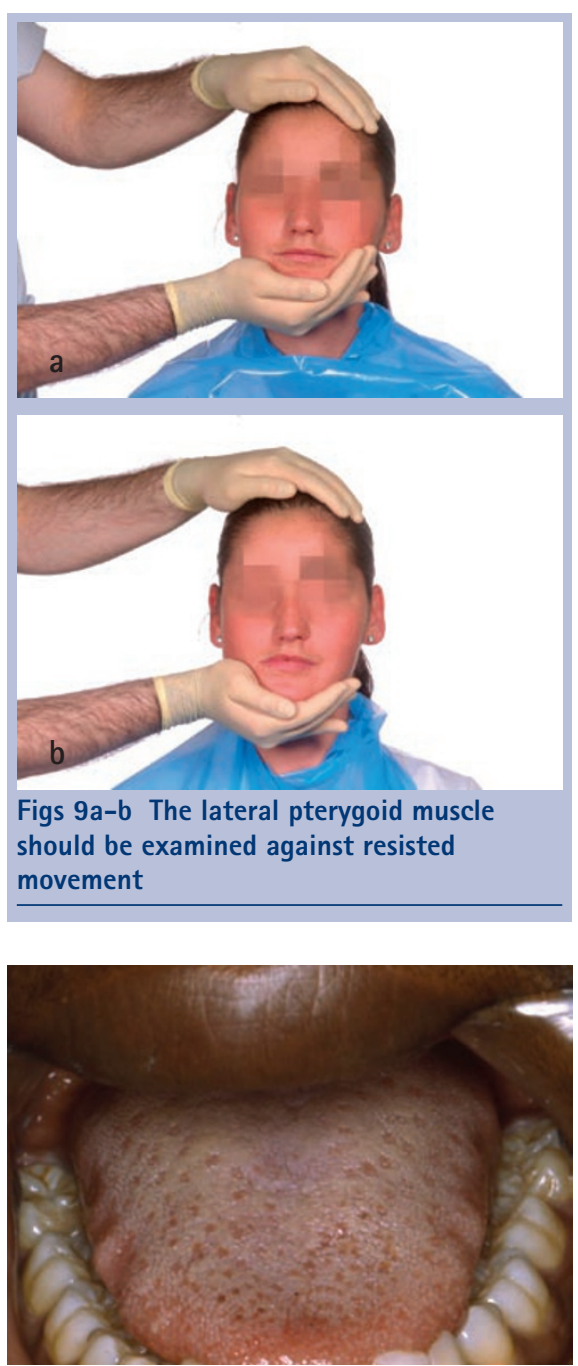

Fig. 10 Scalloping of the lateral border of the tongue

should realise that this muscle cannot be palpated manually or digitally. An often taught method of examining the lateral pterygoid is by placing a finger up behind the maxillary tuberosity and pressing upwards. However, this is a very unreliable way of examining this muscle for several anatomical reasons. Other muscles which are readily accessible include the sternomastoid. It is usually the origin of the sternomastoid which is tender. The digastric muscle is frequently tender over either the posterior belly, which causes discomfort behind the ascending ramus of the mandible under the earlobe, or the anterior belly of the digastric which runs from the hyoid bone to the symphysis of the mandible. This muscle is frequently tender in patients who parafunction on their front teeth.

\section{Signs of parafunction}

The commonly reported signs of parafunction are scalloping of the lateral border of the tongue ${ }^{9}$ (Fig. 10), ridging of the buccal mucosa on the inside of the cheeks (Fig. 11) and abnormal attrition (Fig. 12) or tooth surface loss. Other features are repeated enamel or restoration fracture and otherwise unexplained dental hypersensitivity, either to percussion or temperature. It is important for a dentist to realise when a patient is undergoing abnormal parafunctional activity, sometimes associated with stress, because if left untreated this can proceed to severe destruction or disruption of the dentition. It is important to monitor such tooth surface loss and intervene before the condition becomes gross. This may not always be accompanied by loss of vertical dimension as dento-alveolar compensation can occur. It is, however, essential to diagnose a condition such as this early and take the necessary steps to correct the problem before the situation becomes so gross that multiple complex restorations and/or crown lengthening procedures may become necessary. If this was allowed to happen the patient would have reasonable grounds for complaint.

\section{Occlusal examination}

An occlusal examination ${ }^{1}$ should record whether or not centric jaw relation/ retruded contact position CR/RCP (Fig. 13) and centric occlusion/intercuspal position $\mathrm{CO} / \mathrm{ICP}$, the habitual bite, are coincident. If not, where is the premature contact and is there a slide from $\mathrm{CR}$ to the habitual bite $\mathrm{CO}$ ? If there is a slide is it a large or small slide, is it in the same sagittal plane or is it off to one side or the other? Is there anterior guidance on the canine teeth, which is the ideal, and are there any working or non-working side interferences up to and beyond the canine crossover position? These features should be recorded to enable the dentist to adhere to a conformative approach when performing restorative treatment and to have a baseline for later comparison.

It is important for the dentist to record whether there is freedom in centric occlusion. This is especially important when restoring anterior teeth with, for instance, crowns, as any retrusion of the mandible by placing restorations that are thicker than the teeth were originally could cause immediate TMD symptoms or trauma to the restored teeth due to the mandible being forced distally.

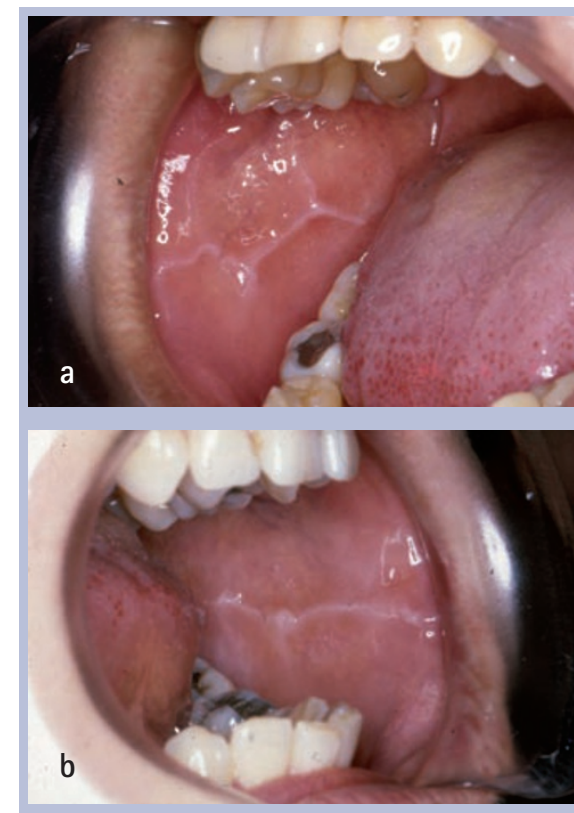

Figs $11 a-b$ Ridging of the buccal mucosa on the inside of the cheeks

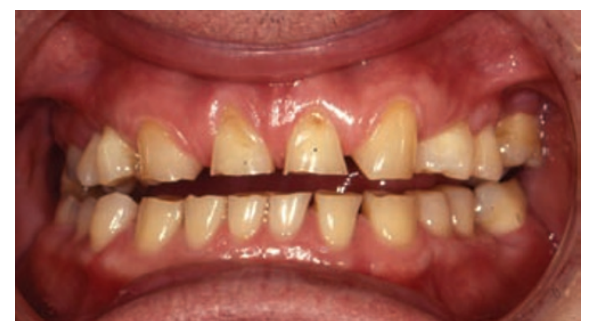

Fig. 12 Tooth surface loss (attrition)

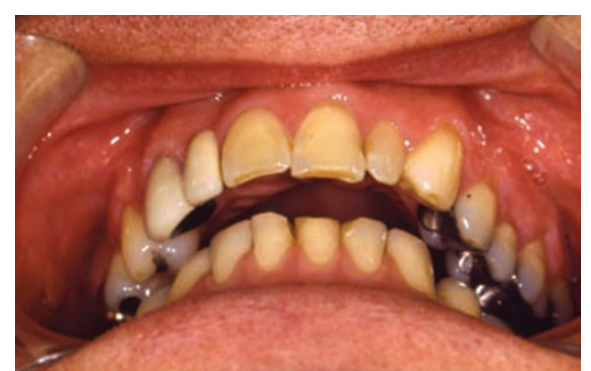

Fig. 13a CR incisal view

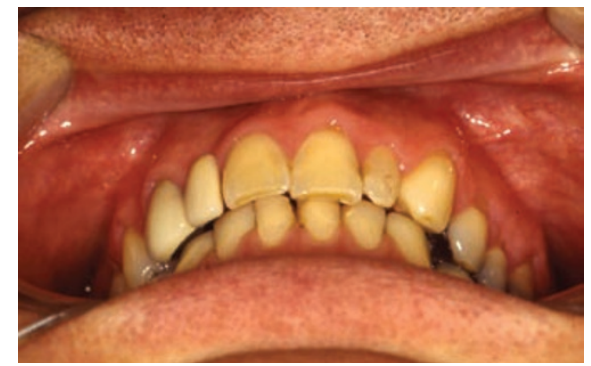

Fig. 13b CO incisal view

Examination of the range of movement, joint sounds, signs of bruxism, joint and muscle tenderness and occlusion should take the clinician no more than two or three minutes to perform and it is their duty to do this for all patients as a prerequisite. 
It is important for the dentist to remember that pain, muscle and joint tenderness are subjective in their severity. What may be severe to one patient may not be to another. Joint sounds vary, not only with the stage and progress of the disease, but on a day to day basis and at different times of the day. Therefore the only true measurable parameter of whether or not a patient's condition is improving is the range of movement.

\section{FAILURE TO DIAGNOSE TMD AND FAILURE TO REFER}

Diagnosis of the commoner TMDs is within the general practitioner's remit. This is not a specialist area. Temporomandibular disorders have been classified by many systems: ${ }^{10,11}$ A) by aetiology. It is generally regarded that the onset of a temporomandibular disorder is usually multi-aetiological and can have predisposing, initiating and promoting factors. There is rarely one cause and one effect. This system is therefore flawed; B) anatomically. These diagnostic systems, however, are also vulnerable as there is commonly an overlap of structures involved; the most valuable classification method which is of most use to general practitioners is $\mathrm{C}$ ) classification by frequency of presentation. ${ }^{12}$

There are rare, uncommon and common disorders. The rare disorders include such conditions as condylar hyperplasia, tumours and joint infections and are very infrequently encountered. Uncommon disorders include conditions such as TMJ involvement in systemic disease such as psoriatic and rheumatoid arthritis. The common disorders include the results of trauma, facial arthromyalgia (myofascial pain), internal derangements and degenerative joint disease such as osteoarthrosis. It is outside the remit of this chapter to list the diagnostic features; these are readily available in other texts. ${ }^{10}$ The general practitioner, however, must be aware of the diagnostic criteria and recognise them when they present.

The differential diagnosis of facial pain can be extremely laborious and difficult to perform. There are several other structures which can give rise to facial pain in a distribution that could mimic a temporomandibular disorder and it is the responsibility of the practitioner to eliminate these before arriving at a final diagnosis.
The most obvious to eliminate first is a dental cause for the symptoms, eg pulpitis, periodontitis or pericoronitis. Other structures that can cause facial pain in this area include ear and sinus infections. These are often misdiagnosed when the patient is in actual fact suffering from a temporomandibular disorder. In a specialist clinic, approximately 30\% of patients have seen their general medical practitioner and may have been prescribed antibiotics or even referred to an ear, nose and throat clinic. Symptoms of these disorders are quite different from a temporomandibular disorder and should be readily identified and excluded. The patient would thereby avoid unnecessary prescription of antibiotics and unnecessary further investigation, potentially detrimental to themselves and costly to the National Health Service.

Facial pain can be associated with disorders of the cranium, the cervical spine, eyes, ears, nose, sinuses, teeth, mouth or other facial or cranial structures. Referred pain from $\mathrm{C5} / \mathrm{C} 6$ nerve root in the cervical spine can lead to pain over the angle of the mandible. Neuralgic pain should not be mistaken for TMD pain. Neuralgic pain is episodic and short, sharp and shooting in nature. Atypical facial pain is a diagnosis used all too frequently but is in actual fact very rare and has bizarre pain distribution frequently extending across the midline. Psychogenic facial pain, although rare, does occur and the term 'somatisation' is applicable. This means transference of psychological symptoms into a clinical manifestation of perceived pain.

Once the dentist has made the diagnosis and is confident that the patient is suffering from a temporomandibular disorder, if he or she feels sufficiently qualified to treat this then appropriate treatment can be instigated. If not the patient should be referred for specialist management. The overwhelming majority of patients are best treated by their own general practitioner as they know the patient more intimately than a clinician who they would have met for the first time. They also know their treatment expectations and would be more able to accurately predict the response to treatment.

Referring a patient for specialist examination or treatment does not mean 'refer and forget'. It is the responsibility of the referring clinician to monitor the patient's progress and if they or the patient are not satisfied with the progress, to undertake appropriate re-referral. It is not uncommon in the management of patients with temporomandibular disorders for patients to be referred to 'specialists' only to be offered potent drug regimes, inappropriate splints or on occasion surgery.

If the dentist feels treatment is outside their area of expertise, and if a patient is not referred promptly upon presentation of their symptoms, then there is a possibility that the symptoms will deteriorate, making subsequent treatment more difficult. An example is for a patient to present with a click which is left untreated and gradually becomes more intrusive and socially embarrassing as it becomes audible to others. This can on occasion progress to locking. The treatment of locking is less successful and more complex than the treatment for clicking. If the treatment had been instigated early on in the patient's course of symptoms, then they would have had a very much improved chance of successful management. The medico-legal implication of this situation is that the diagnosing dentist maintains a responsibility to ensure that prompt and appropriate referral takes place and must monitor their patient's progress.

\section{RESTORATIVE TREATMENT, THE DENTIST AND TMD}

Can a dentist cause a TMD? Yes. In a survey of $230 \mathrm{TMD}$ patients, ${ }^{13} 7 \%$ related the onset of their symptoms to some form of dental treatment. This is not necessarily due to negligent treatment. Excessive or prolonged force on the mandible may play a role. Some individuals may develop symptoms from relatively simple dental treatment that would not lead to symptoms in others. Some are more susceptible than others. Placing a restoration which imbalances the rest of the occlusion may lead to a rapid onset of TMD symptoms and this is one of the very few occasions when direct occlusal adjustment may be a necessary part of treatment. Once the restoration feels comfortable the TMD symptoms should resolve as long as there has not been a sufficient time lapse for them to become chronic.

If a dentist is undertaking a course of treatment in a hitherto asymptomatic patient and TMD signs or symptoms 


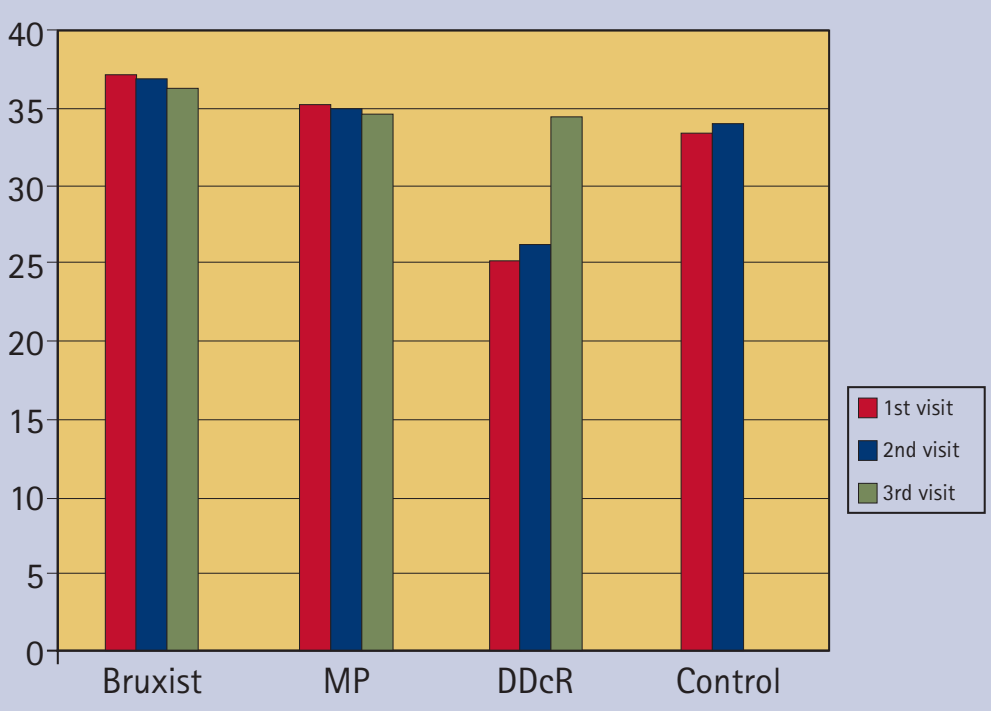

Fig. 14 Bar chart of the mean number of occlusal contacts for the four groups at 1st review (R1) and 3rd review (R3) showing a statistically significant increase in the number of occlusal contacts in the disc displacement with reduction (DDR) group after splint treatment

become evident then the situation should be re-evaluated. In the case of a click suddenly developing, one should be aware of the implications. The occlusion can alter rendering the final restoration occlusally inaccurate. A recent study ${ }^{14}$ examined the number of occlusal contacts in four groups of patients - one control group, one with facial arthromyalgia, one who were bruxists and one with disc displacement. The average pre-treatment number of occlusal contacts in all groups except the disc displacement group was 35 while the number of tooth contacts in the disc displacement group was 26. Post-treatment the number of contacts in three groups had not altered whereas the number of contacts in the disc displacement group had risen to 34 (Fig. 14). The conclusion is that if the disc becomes displaced for whatever reason the occlusion will change. If the dentist is in the middle of a course of restorative treatment involving crowns or bridges and a click develops, placement of the final restoration should be delayed until it can be assessed whether the condition will resolve spontaneously or whether the patient should have the click treated. If the dentist ignores the change in clinical condition and proceeds with placement of the final restoration and the symptoms persist or worsen, he or she could be implicated in the perpetuation of the disorder.

If it is expected there is to be excessive force applied to the mandible or if the mouth is to be kept open for a prolonged period then use a mouth prop and record this in the patient's notes. This is not only for patient comfort. When the mouth is stretched open, among others, the suprahyoid, digastric and lateral pterygoid muscles are active. The superior head of the lateral pterygoid is attached to the capsule and disc; the inferior head to the neck of the condyle. Prolonged contraction of this muscle can tend to pull the disc forwards. If a patient is biting on a prop these muscles relax and closing muscles become active thereby causing less tension on the discal attachments. It is especially important to use a mouth prop in a known TMD patient. The dentist could be regarded as being at fault if this is ignored.

\section{LOSS OF OCCLUSAL VERTICAL DIMENSION AND OCCLUSAL INSTABILITY}

Historically it has been thought that loss of vertical dimension was directly linked to the development of TMD. ${ }^{14-19}$ There is little evidence to support this theory. ${ }^{20}$ The most common situation clinically when a gross alteration to vertical dimension can occur is in the complete denture wearer. Patients are often seen who are markedly over-closed yet this group of patients rarely present with symptoms of a TMD. ${ }^{21}$ Similarly, patients who have lost posterior teeth do not have to have them replaced to prevent later development of a TMD. Indeed the shortened dental arch is often a treatment objective. ${ }^{22}$
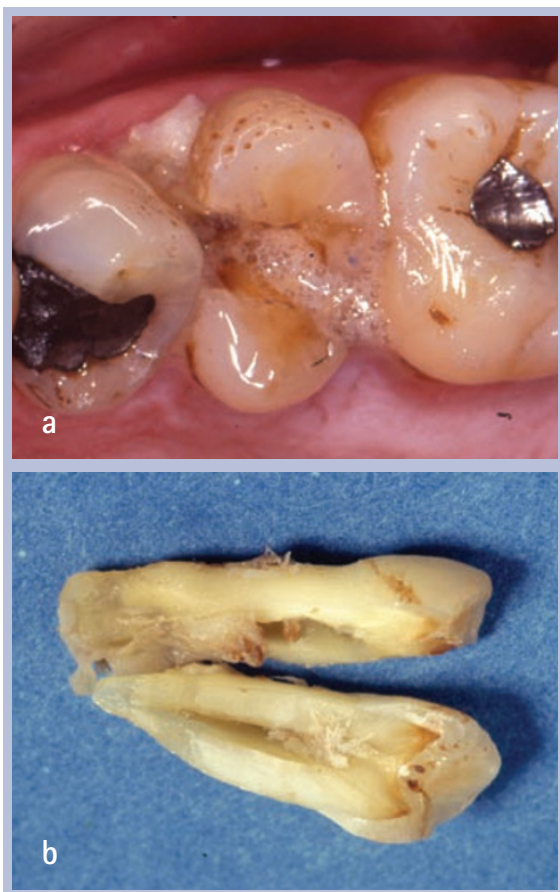

Figs 15a-b Vertical tooth fracture of unrestored tooth caused by parafunction

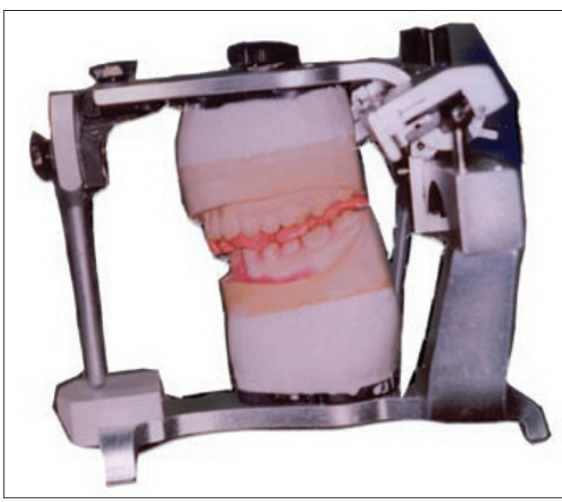

Fig. 16 Diagnostic casts mounted on a semiadjustable articulator

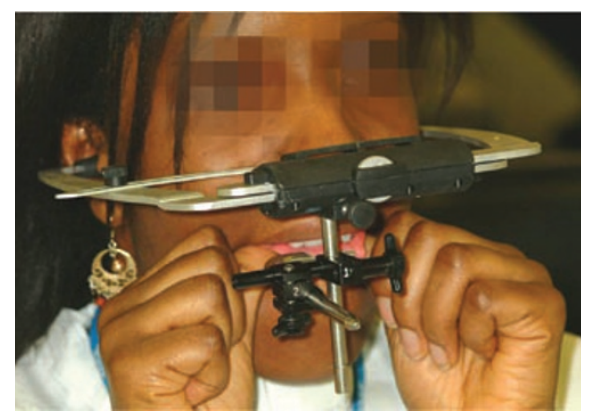

Fig. 17 Face bow transfer

\section{Bruxism and attrition}

Attrition is one of the causes of occlusal instability such as the loss of 'centric stops' and it is important that the restorative dentist is able to recognise the signs. It is these signs that give the clues to the location and extent of damage to the teeth and the corrections that 
are necessary to reduce the wear caused by bruxism. ${ }^{23}$

By recognising signs of instability such as tooth hypermobility, tooth wear, abfractions, periodontal breakdown, stress fractures (Fig. 15), exostosis, muscle enlargement and loss of posterior occlusion, the restorative dentist can interpret the wear patterns and design a treatment plan that will protect the teeth or at least reduce the rate of wear. ${ }^{24}$

\section{The use of a facebow}

A dentist can recognise the signs of occlusal instability not only by taking a thorough history and conducting a complete examination but also by reviewing diagnostic casts mounted on a semi-adjustable articulator (Fig. 16) in centric relation using a facebow transfer (Fig. 17).

Although its use has not been yet supported by evidence-based studies, the use of a facebow is simple, quick and highly recommended when accurate mounting of the casts is required. There appears to be no good reason for not using it.

When restoring anterior teeth, the facebow record provides considerable information for the dental technician and will help to obtain predictable results. If this vital record is not taken, the technician could mis-mount the cast, causing the final restorations to be inaccurate, because without a facebow determination of an occlusal plane could be guesswork.

\section{TMD AND ORTHODONTICS}

The orthodontist has been both accused of causing, and complimented for curing, a TMD. The available literature indicates that a significant percentage of professional negligence actions against orthodontists include allegations of failure to diagnose a TMD, failure to provide timely treatment or failure to refer. ${ }^{25}$ Orthodontists are advised to develop and to implement a specific protocol for the management of patients who develop signs or symptoms of a TMD either before, during, or after orthodontic treatment. ${ }^{26}$

In a review article, Reynders ${ }^{27}$ reviewed 91 articles published since 1966 that discussed the relationship between orthodontics and TMD. He reported a wide variety of conflicting opinions on the relationship between orthodontics and TMD but dismissed many as they were the authors' personal opinions and were unsubstantiated.

Sample studies ${ }^{28-30}$ indicate that orthodontic treatment is not responsible for creating a TMD either at the time of treatment or later, regardless of the orthodontic technique used, whether or not involving extractions and whether or not fixed or removable appliances were used. Moreover, other studies ${ }^{31,32}$ report that orthodontic treatment is not necessary to cure signs and symptoms of temporomandibular dysfunction but can form part of an overall treatment plan when appropriate.

Thirty-one articles were initially identified by a systematic search. ${ }^{30}$ These studies found no relationship between orthodontic treatment and TMD prevalence. Orthodontically treated patients, regardless of the type of therapeutic intervention, have no more and no fewer TMD symptoms than those found in the general population.

The literature therefore does not support a causative link between orthodontic treatment and TMD. ${ }^{28}$ The fact that a TMD may start soon after cessation of orthodontic treatment merely reflects the age of the patient. It is often in the late teens that a TMD would develop irrespective of whether or not orthodontic treatment had been undertaken and any link is usually coincidental. If a TMD develops during the course of treatment then this should be addressed in the usual manner and if the orthodontist is uneasy, then the patient should be referred for advice.

One consistent link between a basal bone and incisal relationship and risk of development of a TMD that the orthodontist should be aware of is the presence of an anterior open bite ${ }^{33}$ as this condition predisposes to development of a TMD in any case.

\section{TMJ IMAGING}

There is debate as to whether there is any routine need for TMJ imaging. ${ }^{33}$ The recent IRMER Guidelines ${ }^{34}$ indicate that it is our responsibility to minimise the patient's exposure to ionising radiation and radiographs should only be taken when clinically necessary. The same guidelines apply to patients with temporomandibular disorders. Many radiographs appear to be taken arbitrarily or merely to confirm a clinical diagnosis when in fact they are not necessary and add nothing to the diagnosis or treatment plan. Radiographs can be used to assess gross abnormalities in a temporomandibular joint, such as osteophyte formation or sclerosis, and to look for signs of degenerative joint disease such as erosion or loss of cortical outline of the mandibular condylar head or the fossa.

Much importance has in the past been attached to the role of radiographs in determining a specific position of the condyle in the fossa to which an occlusion should be restored. This is factually incorrect. Studies have shown that it is impossible to determine joint space even with 'corrected' TMJ views using a head positioner when the centre beam is directed along the long axis of the condylar head. The condylar angle varies intra- as well as inter-individually and has been reported as being from $0^{\circ}$ to $50^{\circ}$ to the sagittal plane.

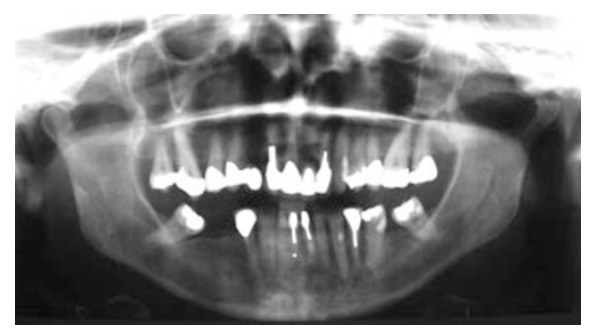

Fig. 18 DPT showing normal right condyle and eroded left condyle

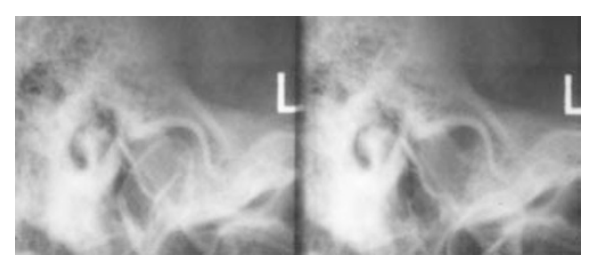

Fig. 19 Transcranial oblique lateral closed and open views

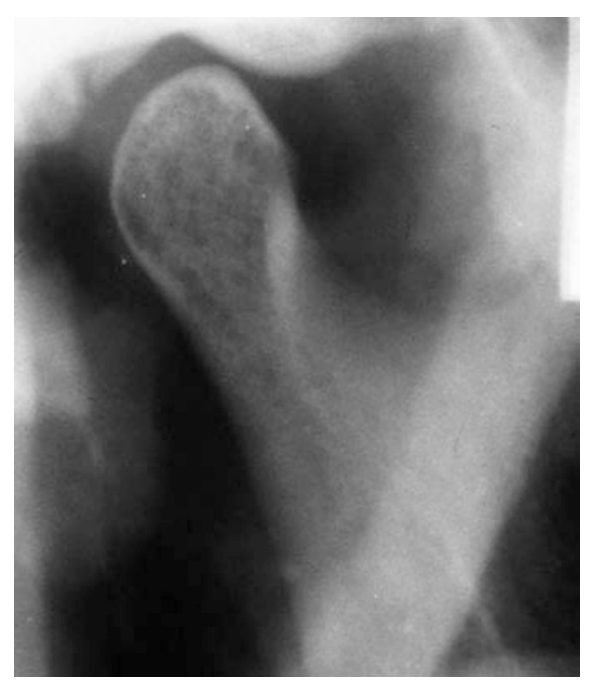

Fig. 20 Transpharyngeal view of mandibular condyle 
This angle also varies from one side to the other. A study on head positioning variations ${ }^{35}$ measured 13 different parameters in post-mortem specimens and found statistically significant differences in each of the measurements undertaken when the head position or the tube angle was altered by as little as $5^{\circ}$. When examining temporomandibular joints radiographically, the load bearing part of the joint is not visualised due to the angle of the centre beam. More than $60 \%$ demineralisation is needed before erosions are radiographically evident. The surfaces of the joint and fossa are covered by fibrous tissue which is not visible on a standard radiograph therefore early changes will not be seen. On a standard radiograph the disc cannot be seen. For all these reasons radiographs have limited value and should not be taken unless there is a good clinical reason for doing so. It should be regarded that there is only value in taking a radiograph if the clinical treatment plan will be altered by the outcome.

The standard scan view taken is a panoral radiograph (DPT) (Fig. 18). The joint relationships cannot be observed as the patient has to protrude the mandible to bite on the incisal block. This is, however, a useful scan if looking for the presence of gross factors such as osteophyte formation or erosion. Another standard view is the transcranial oblique lateral (TOL) (Fig. 19). This is taken at a $25^{\circ}$ angle through the contralateral side to avoid super imposition of the petrous temporal bone, so again this does not show the load bearing part of the joint, rather the lateral pole of the condyle and the lateral rim of the fossa. It is only valuable for looking at gross changes. A transpharyngeal view (Fig. 20) can be taken to delineate any pathology in the head of the condyle. A problem with this view, however, is that the patient must be able to open sufficiently wide for the head of the condyle to clear overlying structures and this is often not possible.

Other imaging techniques are available, such as arthography (Fig. 21). However, this is now becoming less common as it is an invasive procedure and the results, without considerable practice, can be difficult to interpret. This technique is useful for assessing the degree of disc displacement and is also used for determining the presence of perforation in the disc. The

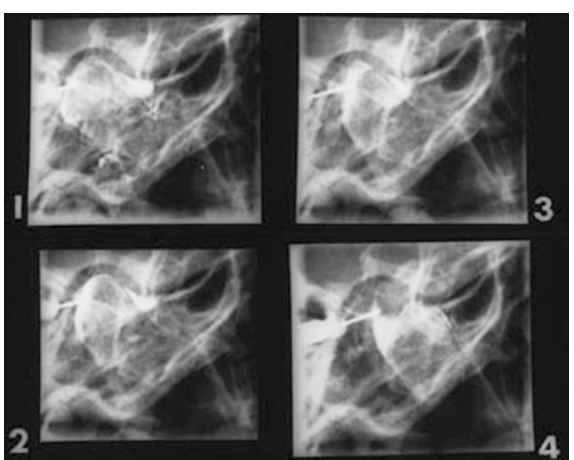

Fig. 21 Arthrogram of anterior disc displacement. 1 = closed, 2 = part open preclick, 3 = part open post-click, 4 = fully open post-click

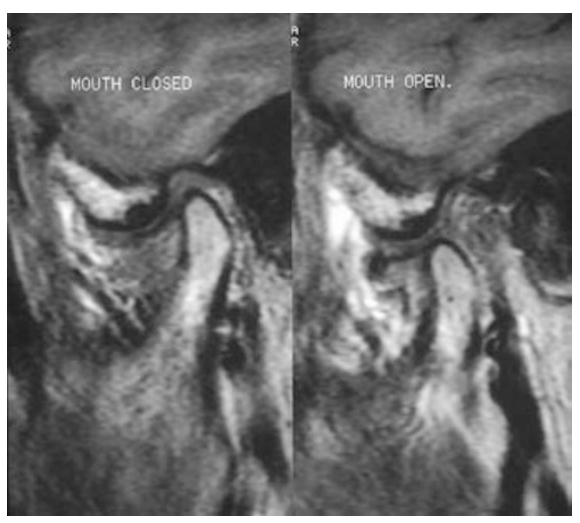

Fig. 22 Magnetic resonance scan

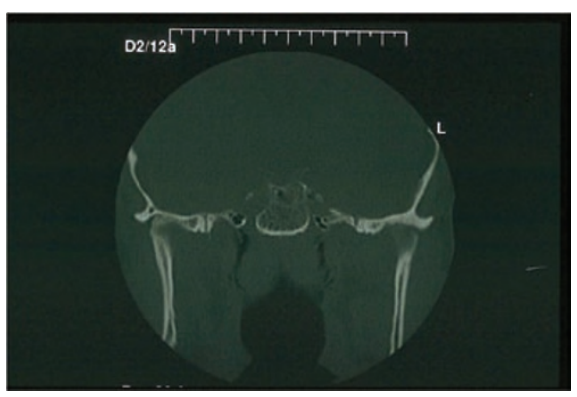

Fig. 23 Sagittal CT scan of mandibular condyles showing degenerative disease

use of arthography has been largely superceded by magnetic resonance (MR) imaging (Fig. 22). This gives accurate information in relation to not only the bony components but also the soft tissues. There is, however, a significant cost implication in undertaking this special test and also in reporting the results, which needs to be done by an experienced radiologist. Computerised tomography (CT) (Fig. 23) scanning has a place in imaging the hard tissues and high resolution examination can be performed. This can be done not only of the joints but also of the bony structures in the immediate surrounding area such as the petrous bone, middle ear and mastoid air spaces. The position of the condylar head can be examined and evidence of inflammatory or degenerative bone disease can be investigated. Soft tissue or meniscal disorders of the temporomandibular joint, however, would not be demonstrated by CT. This is a special test which carries a high radiation burden and should only be employed if surgery is contemplated. More information can be gained from MR imaging.

Any of these tests should be undertaken only if their outcome is going to significantly affect the treatment plan, otherwise they are difficult if not impossible to justify. In a dedicated TMD clinic, less than $20 \%$ of all patients have any radiographic or other imaging undertaken because, as a general rule, it is not needed.

\section{OCCLUSAL ADJUSTMENT}

There is insufficient evidence to suggest that any occlusal treatment is as, or more effective than any other rehabilitation treatment in TMD. There is also insufficient evidence to support the generalised preventive influence of occlusal adjustment or orthodontic correction of malocclusion on TMD development. ${ }^{36,37}$ Controlled studies of occlusal factors and TMD show either no relationship or at best only a weak correlation between specific variables and TMD. ${ }^{38-40}$

When considering those authors who argue that specific occlusal factors might make some biological contribution to a TMD and thus should not be ignored, ${ }^{41,42}$ it should be remembered that a biological system will frequently adapt to various morphologic features until stability is achieved. Other authors ${ }^{43}$ suggest that some occlusal variables may be a result rather than a cause of TMD. It is apparent when treating a patient with an occlusally balanced appliance that the mandibular position can alter quite markedly as treatment progresses and painful muscles relax. For this reason what initially might be deemed to be an occlusal interference or premature contact at the onset of treatment might not be one at the end. As an initial therapy, occlusal adjustment is therefore not recommended as jaw and tooth relationships cannot be accurately determined in the presence of pain. The approach of "pick up a handpiece and remove interferences at the first visit' is not defensible.

Much of the basis for the idea that 'occlusion' plays a major role in the aetiology of TMD comes from observing the results 
of various occlusal therapies. Success in therapy, however, does not demonstrate a causal association between occlusion and development of a TMD. Again, many of the theories purported to support the association are totally unsubstantiated.

The literature suggests that occlusal equilibration, therefore, should not be provided as an initial therapy for TMD patients and occlusal equilibration should not be performed to prevent TMD signs or symptoms. ${ }^{13,44-46}$ It has also been suggested that if an anterior repositioning appliance successfully treats symptoms of a internal derangement then the occlusion should be restored to the treatment position. Contrary to what some practitioners advocate, however, occlusal therapy is not needed to maintain a TMD patient's long-term symptomatic improvement. ${ }^{47-49}$

Since occlusal treatments are typically irreversible and the evidence on their therapeutic or preventive effects on TMD is insufficient, it is recommended that reversible treatment such as self-care, splints, physiotherapy and pharmacotherapy should always be used initially to manage signs and symptoms of TMD. As symptoms of pain and dysfunction in a TMD patient may come and go without any obvious change in any recognisable factor, one must be very hesitant about introducing any permanent changes in any part of the system..$^{50}$ If occlusal adjustment or equilibration is deemed necessary for other clinical reasons then this should always be planned on study models mounted on a semi-adjustable articulator before irreversible and permanent changes are made to the patient's natural dentition. ${ }^{51}$ In this way the sequence of alterations can be carefully planned and it can also be determined whether the desired result is actually achievable. In addition extensive occlusal adjustment should only be carried out after a period of successful splint therapy which would indicate whether provision of an 'improved' occlusion would benefit the patient's symptoms.

It is acknowledged that occlusal treatment can be used successfully to correct an uncomfortable occlusion in a patient with or without TMD. For example, a patient who reports an uncomfortably high, recently placed restoration can be treated with occlusal adjustment of this restoration as the primary treatment.

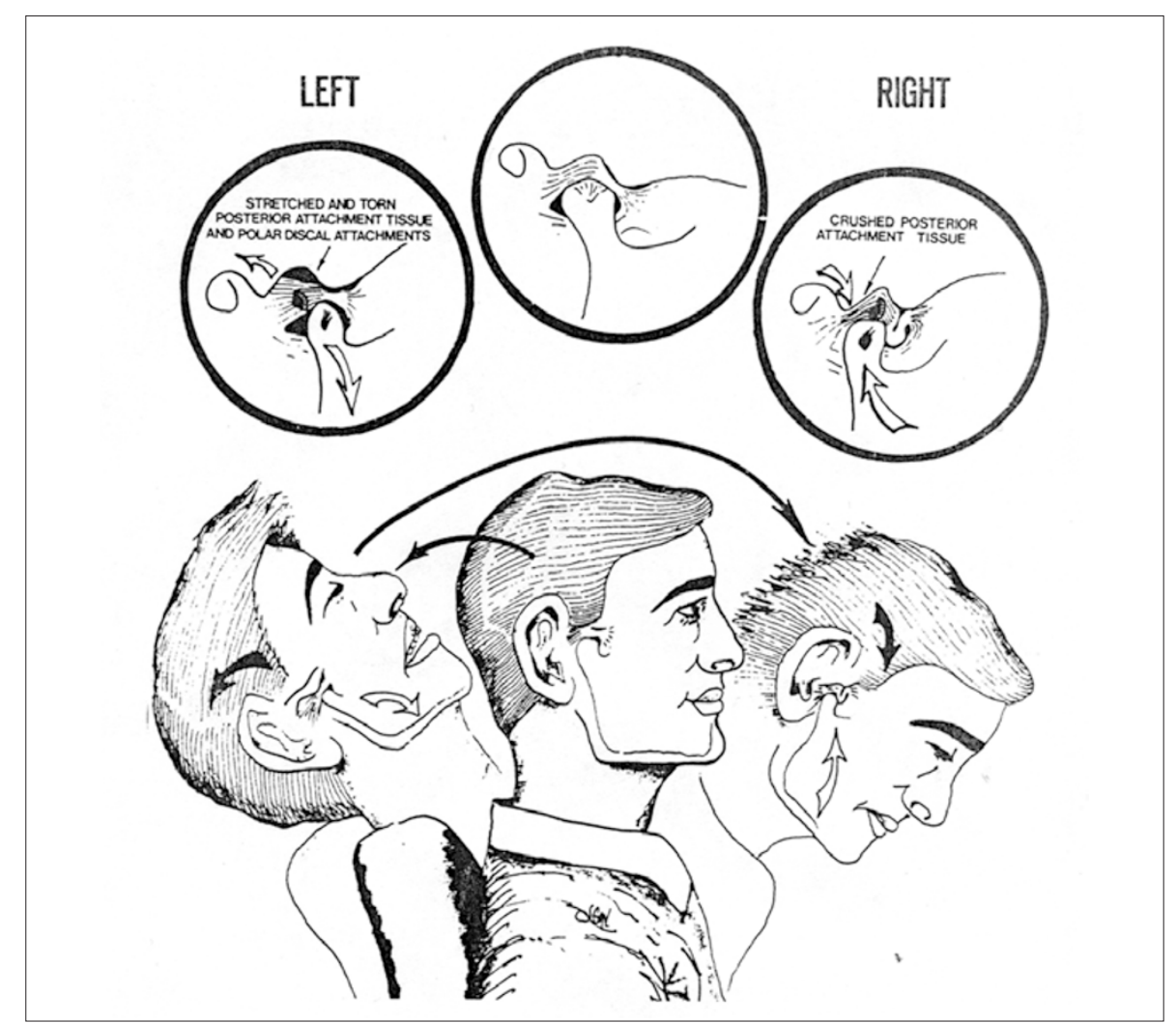

Fig. 24 Perceived head and jaw movement following a rear end impact highlighting the trauma to the disc. (Figure reprinted from the Journal of Oral and Maxillofacial Surgery, volume 45, S. Weinberg and H. Lapointe, Cervical extension-flexion injury (whiplash) and internal derangement of the temporomandibular joint, pages 653-656, Copyright (1987), with permission from Elsevier. http://www.joms.org/home)

Given that there are other, less invasive approaches available, and TMD symptoms may be self-limiting, it would seem that occlusal adjustment is not indicated unless additional evidence is forthcoming. . $^{52,53}$

\section{RTA - WHIPLASH}

The term whiplash expresses the characteristic head and neck motion that occurs when a relatively rigid thorax is suddenly accelerated or decelerated independently of the head. It simply describes a hyperextension/flexion injury to the soft tissues of the neck. It would suggest that after the hyper-extension phase, a rebound or recoil injury in hyper-flexion occurs, hence the use of the term 'whiplash' (Fig. 24). Clinicians should be aware of the fact that trauma to the temporomandibular joint, mandibular muscles and dentition can be involved in such an injury and it is essential that a detailed examination is done and adequate records are kept. ${ }^{54-56}$ The typical situation in which this can occur is when the occupant of a motor vehicle undergoes a sudden collision, typically in a road traffic accident (RTA) when the front end of one car (the bullet vehicle) strikes the rear end of another car (target vehicle). It is believed that the injury is not the result of direct physical impact forces or direct trauma to the occupant of the vehicle by contact with an object inside the target vehicle; rather it is suggested as being an indirect physical reaction to forward acceleration of the target vehicle, namely indirect trauma, released through acceleration/deceleration of the occupant's head, neck and mandible. The result may be bony or soft tissue injuries or both and this may lead to a variety of clinical manifestations which are grouped under the name 'whiplash associated disorder'.

Unfortunately these disorders are poorly defined. The signs include a wide range of often semi-covert injuries but symptoms vary widely. Many injuries cannot be detected by radiographic or even manual examination. It has been postulated that the severity of the whiplash associated disorder may be affected by many factors such as vehicle type, restraint type, seatbelts or lap straps, airbags and headrests, the occupant's position in the vehicle, the type, the angle and the speed of impact and the degree of structural damage. It 
has also been suggested that a degree of damage can be related to whether or not the accident victim had the time to brace themselves if they could see the impact coming and whether or not they had their mouth open at the time of impact. An additional and unfortunate confusion arises from the fact that the diagnosis of a TMD associated with a whiplash injury has been extended to include practically every known dysfunction affecting the articulatory system.

If a patient presents with clinical signs and symptoms of a temporomandibular disorder following a whiplash injury, the disorder should be treated as one would treat any other similar TMD, noting the potential trauma from the whiplash injury. The date, time and circumstances of the accident should be noted as well as the date of onset of symptoms. The patient may become aware of acute symptoms immediately after the time of the accident. This will normally be manifest by inability to open the mouth comfortably, inability to chew, forced change to a soft diet and pain from the areas of the mandibular muscles or from the joints themselves. It is also not uncommon for a click to develop immediately after a whiplash injury. Alternatively, due to severe symptoms from the cervical spine, the TMD symptoms might not become apparent until the pain from other structures subsides. This can take three to four weeks from the time of the accident. Symptoms may well have been present since the time of the impact but have been masked by the severity of the other problems. It has been suggested that development of an internal derangement after a whiplash injury is as a direct result of trauma to the mandible in that the pull of the lateral pterygoid muscle in combination with the force of the trauma causes stretching of the posterior attachment of the disc and a resultant antro-medial displacement. It is thought that this is particularly significant if the trauma occurred when the mouth was open. The literature, however, is at variance in relation to cause and effect. ${ }^{55}$

The dentist's role is to manage the temporomandibular disorder as they would any other similar disorder but to keep strict records of the onset of the symptoms in relation to the date and time of the initial injury and keep accurate follow up records. Notes should also be made of effect of the symptoms on day to day function such as diet, chewing and yawning, the effect on hobbies and other quality of life aspects and any perceived disruption to the occlusion.

Due to the force of the impact, patients may present with broken teeth or broken restorations. This occurs because during the hyperextension phase of the injury, the mandible 'lags behind' the rest of the skull and during of the hyper flexion phase, the mandible forcibly closes causing an impact between the upper and lower teeth. In these circumstances direct trauma to the dental tissues is not unusual and should be noted.

\section{HEADACHE}

Over recent years the dental and national press has contained many articles about the dentist's role in the management of headache. This is inappropriate ground for the dentist. Headache is a symptom; it is not a disease. The clinician most trained and skilled in the diagnosis of headache is a neurologist, not a dentist.

The Classification and diagnostic criteria for headache disorders, cranial neuralgias and facial pain ${ }^{57}$ is a book of 96 pages which is devoted solely to the classification of headache. There are 13 primary classifications, each with several sub-classifications. The headache which appears to be associated with a temporomandibular disorder is classification number 2: tension type headache. This is further divided into sub-classifications including episodic and chronic. The TMD associated headache, according to the diagnostic criteria, is 2.2: chronic tension type headache. This is further sub-divided into whether or not the pericranial muscles are associated. The diagnosis is now, therefore, 2.2.1: chronic tension type headache associated with a disorder of the pericranial muscles. A fourth digit code number then indicates the most likely causative factors of which nine are listed. The sub-classification relevant to TMD patients is number 2 associated with oro-mandibular dysfunction. We therefore have our final classification, 2.2.1.2: chronic tension type headache associated with disorder of the pericranial muscles and associated with oro-mandibular dysfunction. This is the only headache that dentists are qualified to diagnose.

If a patient is referred to a dentist for treatment of headache, this should only be undertaken if usually accepted diagnostic criteria for a temporomandibular disorder also exist as the primary features and if headache is also one symptom. Headache is not a sole diagnostic feature of a temporomandibular disorder.

\section{EVIDENCE-BASED TREATMENT}

All treatment should be evidence-based. Numerous treatments, either on their own or in combination, have been proposed in accordance with various aetiological theories of TMD. A wide range of pharmacological, occlusal alteration, psychotherapeutic, and physiotherapeutic treatments have also been suggested for the management of TMD, mainly aimed at the reduction of pain and improving the range of movement.

This is possibly the area of most contention in TMD management. Several treatments have been proposed which are not evidence- or scientifically-based and when the literature is critically evaluated it is obvious they have little rationale. It is not sufficient to argue that if a treatment modality is published in a journal, which may not be subject to peer review, be un-refereed, or is accessible through the Internet, then it is validated. The dentist has a responsibility only to prescribe treatment for patients that has a proven therapeutic value and ignorance of currently accepted views of what a reasonable body of dentists would do is not an excuse. Examples of this include prescription of supra-occluding inlays on posterior teeth or of so called pivot appliances. Those who advise these have failed to appreciate that the mandibular muscles are behind the fulcrum of either of these interventions so they can have no hope of achieving the perceived objective of distracting the condyle from the fossa. Another example is the arbitrary addition of composite to the occluding surfaces of the teeth in an attempt to 'stabilise or improve' the bite. This should be avoided unless it forms part of an overall pre-planned treatment prescription that has been developed in line with sound clinical principles after careful occlusal analysis of mounted study casts and possibly after a period of successful splint therapy. 
Drug therapy

Non-steroidal anti-inflammatory drugs (NSAIDs)

These drugs should be not be given to patients who have a history of asthma or gastric irritation including peptic ulceration. NSAIDs need to be taken on a regular basis to maximise their anti-inflammatory effect. Patients should be counselled that it may take from three to five days before the anti-inflammatory effect is realised. Prescription of these drugs without checking the medical history is negligent.

\section{Muscle relaxant drugs}

Many drugs are suggested as 'muscle relaxants.' These range from tricyclic antidepressants to benzodiazepines. The benzodiazepines are the only drugs falling into this category that have a recognised pharmacological muscle relaxant effect but it must be remembered that these drugs are licensed as anxiolytics, not muscle relaxants. Patients who exhibit acute muscle spasm can be prescribed benzodiazepines. They are useful in patients with disc displacement without reduction of recent onset, to relax lateral pterygoid spasm if this has been diagnosed clinically. It should be taken about half an hour before sleep especially if there is a suspected nocturnal parafunctional habit. Temazepam oral suspension is the drug of choice. It must be prescribed with the patient's general medical practitioner's knowledge and can be given for up to four weeks. If the muscle relaxant effect has not been realised by then it should be discontinued. The oral suspension is preferred as the patients can easily titrate the dose themselves to keep the effect to a maximum but avoid side effects such as drowsiness on waking. $10 \mathrm{mg}$ at night is the recommended starting dose and this can be reduced sequentially. It should not be given to children under 12 years of age.

Due to recent changes in legislation, if temazepam oral suspension is to be prescribed privately, the clinician must apply to their primary care trust for a special form for prescription (FP10PCD) as temazepam is now a controlled drug.

Intra-articular steroid injection can be prescribed in cases of intractable joint pain or advance degenerative joint disease. The patient should be counselled, however,

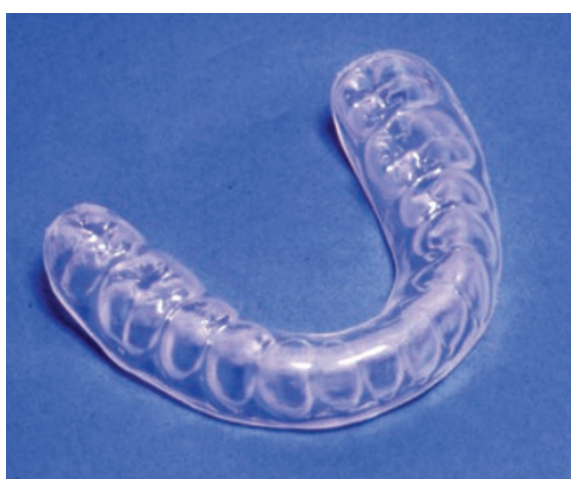

Fig. 25 Soft bite guard

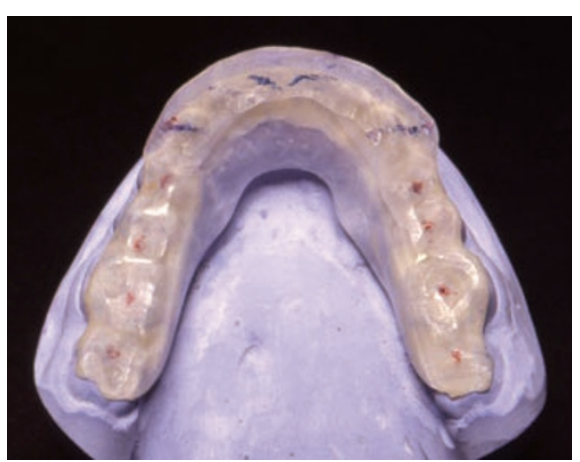

Fig. 26 Stabilisation splint

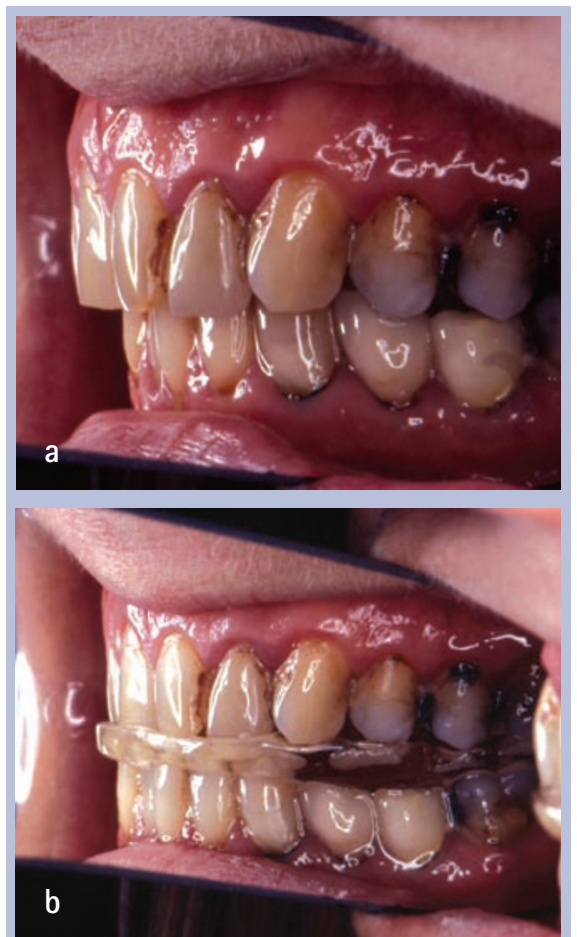

Fig. 27 Anterior repositioning splint: (a) teeth in occlusion without splint; (b) teeth in protrusive occlusion with splint in place

that using an 'injured joint' with symptoms artificially suppressed could cause further damage. Supportive advice should be given regarding rest and the need to adhere to a soft diet. The drugs most commonly used are triamcinolone and depomedrone. Intra-articular steroid injections can be repeated but it has been suggested that further erosion can occur with repeated injection.

Lele and Hooper ${ }^{58}$ published a protocol in the Cochrane Library on the efficacy of pharmacological agents in the management of pain in patients with TMD. They suggested that sufficient data do not exist upon which pharmacological intervention can be based. In the interim, dentists who treat TMD patients should consider the use of many drug classes as being 'non-validated' clinical practice. Considerable difference of opinion exists about the efficacy of different drugs and clinicians, therefore, are at present unable to make informed treatment decisions that will effectively manage pain.

\section{Physiotherapy}

The available literature suggests that physiotherapy started early in the course of any musculo-skeletal disorder significantly reduces the duration of symptoms. This treatment option is beneficial to the TMD patient when there is muscle involvement and the dentist should be aware that early referral is preferred before the symptoms become chronic.

Several jaw exercises have been suggested as being effective in achieving strengthening of the muscle groups which control the affected joints. Such exercise may involve movement against resistance to improve muscle strength and positive correction of any deviation of mandibular movement. Care, however, must be taken to avoid excessive exercise or effort during the acute phase to prevent further damage to the joint by exceeding its reduced functional capacity or by further compromising a displaced disc.

\section{Splints}

\section{Soft bite guard}

The commonly used soft poly-vinyl vacuum formed appliance (Fig. 25) has limited value. Some patients who use these get better but they possibly represent the group of patients who would get better anyway as their symptoms are self-limiting. In a percentage of patients these appliances can make symptoms worse as the patient is so aware of having something compressible between the teeth that this increases parafunction. 


\section{Stabilisation splint (SS)}

A high clinical success rate of SS therapy (Fig. 26) in reducing signs and symptoms of myofascial pain has been reported..$^{59-61}$ The long-term success rate of SS has been demonstrated in several studies $^{62}$ and there is no need in the overwhelming majority of patients for 'second phase' permanent alteration of the patient's occlusion either by means of orthodontic treatment or by advanced restorative treatment.

\section{Anterior repositioning splint (ARPS)}

This splint (Fig. 27) was found to be highly successful in reducing or eliminating TMJ clicking ${ }^{63-66}$ when it could be demonstrated at the chairside that the click was eliminated by asking the patient to open and close from a protruded position. On occasion when the patient does this it is painful and/or the click becomes worse and in these circumstances ARPS treatment is not advised. Davies and Gray ${ }^{65}$ showed that $88 \%$ of patients who wore the splint on a 24 hour per day regime had a statistically significant improvement over a three month period. They concluded that the ARPS is an appropriate treatment for patients suffering from disc displacement with reduction provided that it is used for 24 hours a day throughout the treatment period. Splint therapy should be stopped immediately if any of the splint fractures leaving some teeth uncovered and thereby changing it into a partial coverage appliance.

An ARPS is a successful long-term treatment for the management of disc displacement with reduction without the need to resort to any form of permanent second phase treatment.

\section{Localised occlusal interference splint}

This is an appliance (Fig. 28) usually made for the upper arch with ball end interference wires which intentionally interfere with centric occlusion and are hypothesised to increase the load on the periodontal proprioceptors of the teeth involved, thereby discouraging clenching or bruxism. ${ }^{67}$ The dentist should instruct the technician to ensure the ball end wires are constructed of soft solder thereby preventing damage to the teeth. This is an appliance which is of benefit to the patient who parafunctions in $\mathrm{CO}$ but is

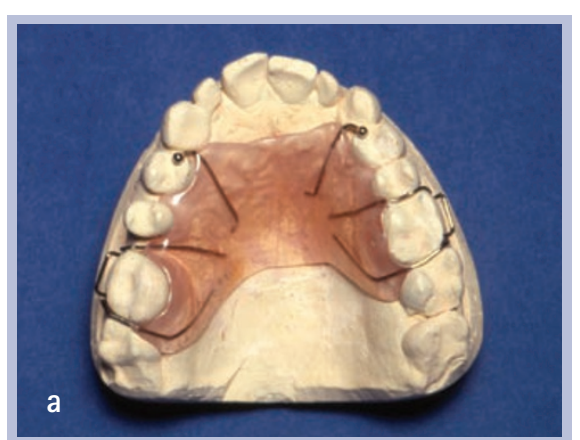

\section{Mandibular advancement/ snoring appliances}

Dentists are being approached by patients and commercial companies with increasing frequency to provide appliances for those who suffer with anti-social snoring. Several designs are proposed, some are custom made but many are not. The practitioner should be wary of prescribing non-custom made appliances.

As a profession we warn patients away from 'boil and bite' mouthguards. They do not fit well, they are not made to the dentist's prescription and they do not distribute forces evenly, rendering their benefit dubious. The same is true of other pre-formed occlusal appliances. The provision of an 'anti-snoring appliance' requires carful collaboration between dentist and technician to determine whether the articulatory system will support such a splint. If there is any doubt about the periodontal status this should be addressed before suggesting treatment. Considerable forces are transmitted to the teeth and supporting structures by wearing these and it is the dentist's responsibility to ensure that exemplary oral hygiene, bone support and periodontal condition exist otherwise direct damage to the tissues can result.

The degree of mandibular protrusion should be carefully monitored. Too little, and the appliance will not work. Too much and the appliance can have a detrimental effect on the teeth, periodontium and TMJs and mandibular muscles leading to clinical damage.

Pre-formed anti-snoring appliances are inappropriate when custom made, readily adjustable ones are available. ${ }^{69}$ Partial coverage pre-formed anti-snoring appliances are unjustifiable. Some are packaged with questionnaires for the dentist and patient to complete including questions about 'major life events, drug abuse and somatisation'. To the majority of snorers (and dentists) such questions are irrelevant and often inappropriate.

Patients may have sought recourse to sleep clinics and will have had sleep apnoea investigation. ${ }^{70}$ In the face of this, the dentist has the responsibility to critically evaluate such dental treatments before suggesting them to patients and thereby endorsing their use.

In general terms this applies not only to 


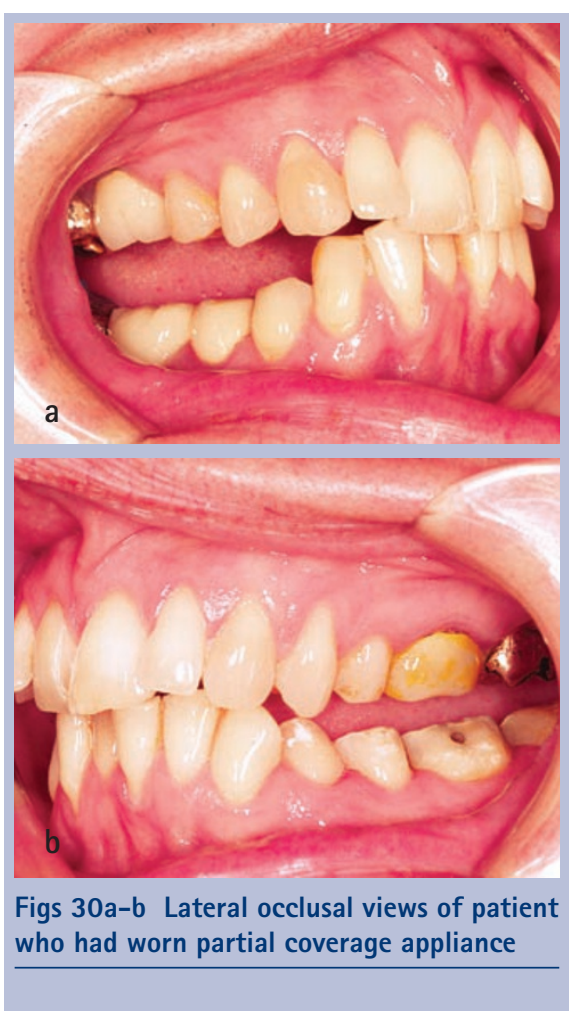

suggested appliance use but also to courses which promote a series of 'quick fix' appliances and courses which have the objective of covering 'all you need to know' about a topic in a day. The dentist must be aware of and be able to freely discuss the success rate of such treatments and, very importantly, other alternatives. It must be explained to the patient pre-treatment that there are limitations and that there is no guarantee of success in all cases.

\section{Partial coverage splints}

Unopposed teeth over-erupt. This is basic undergraduate knowledge. Occlusal splints must be worn to a given prescription, often for considerable periods of time, to be effective. If a splint does not cover all the occlusal surfaces in an arch, unopposed teeth will continue to erupt creating an iatrogenic malocclusion. This applies to both anterior and posterior partial coverage splints and their use can never be recommended..$^{71}$

Figure 30 shows the occlusion of a patient who had worn a posterior onlay splint for some years. When she closed into $\mathrm{CR} / \mathrm{RCP}$ and also into CO/ICP, the posterior teeth were several millimetres apart (the thickness of the splint). The appliance had provided no anterior coverage but had permitted the incisors and canines to over-erupt, and caused intrusion of the posterior segments. In a reverse situation an anterior splint would permit the posterior teeth to over-erupt, so that when the splint was removed the anterior teeth would be apart and anterior guidance would have been lost.

\section{Dahl concept}

This is a technique where a form of partial, usually anterior, coverage is used to gain space. $^{72}$ This is entirely different as it forms part of a restorative treatment plan and is thus a carefully planned procedure to either create space for the restoration of a worn dentition or to allow for planned re-eruption to take place. This treatment is carried out under careful supervision and monitoring and is pre-planned to achieve a predicted result. This should be aimed at ultimately enhancing and improving the existing occlusion. As long as the objectives have been carefully defined and discussed with the patient this treatment is justifiable as being in their best interests. Some anecdotal observations have reported development of symptoms of a TMD following treatment with a Dahl appliance, however, this is not supported by the literature and if symptoms do occur they are consistently reported as being transient.

There is therefore no place in TMD management for partial coverage appliances directed towards resolution of TMD symptoms and their use is medico-legally indefensible. These permit unbalanced and unmonitored tooth movement which cannot be predicted, with subsequent, and sometimes severe, occlusal disruption.

\section{GLOSSARY OF TERMS ${ }^{73}$}

Abfraction. The pathological loss of hard tooth substance caused by biomechanical loading forces.

Anterior bite plane. An individually fabricated anterior guide table that allows mandibular movement without the influence of tooth contact and facilitates the recording of maxillo-mandibular relationships.

Anterior repositioning splint. An intraoral appliance constructed to temporarily alter the position of the mandible relative to the maxilla used in the management of disc displacement with reduction (clicking).

Articulator. A mechanical instrument that represents the temporomandibular joints and jaws to simulate some average mandibular movements.
Bruxism. The paroxysmal grinding of teeth.

Clicking. A cracking or snapping noise from the TMJ evident on excursions of the mandible usually associated with an internal derangement of disc displacement with reduction.

Crepitation. A crunching or grating noise from the TMJ during movement.

Dahl concept. This describes a method of creating inter-occlusal space in a localised part of the mouth to enable placement of restorations on worn teeth but also has use in a variety of other clinical situations.

Decreased occlusal vertical dimension. A reduction in the distance measured between two anatomic points when the teeth are in occlusal contact.

Disc. A sheet of dense fibrous tissue interposed between the head of the condyle and the glenoid fossa.

Disc displacement with reduction. A condition in which the TMJ disc is displaced at rest (usually antero-medially) but resumes a normal position on mandibular movement usually accompanied by a click.

Disc displacement without reduction. A condition in which the TMJ disc is displaced at rest and does not resume a normal position on mandibular movement.

Disc perforation. A tear in the articular disc permitting communication between the superior and inferior joint spaces.

Dislocation. A non-self-reducing displacement of the mandibular condyle out of the glenoid fossa and anterior to the articular eminence leaving the patient unable to close their mouth.

Facebow. A calliper-like instrument used to record the spatial relationship of the maxillary arch to anatomic reference point(s) and to transfer this relationship to an articulator.

Facial Arthromyalgia (Myofascial Pain). The most commonly reported TMD characterised by a dull regional ache which is worse with function. Additional symptoms include muscle tenderness, TMJ tenderness, a reduced range of mandibular movement and joint sounds can be intermittently present.

Internal derangement. A deviation in position or form of the tissues within the TMJ capsule; an abnormal relationship of the disc to the condyle, fossa and/ or eminence. 
Localised occlusal interference splint. A device constructed to intentionally interfere with centric occlusion to discourage bruxism.

Locking. An internal derangement of the TMJ of with disc displacement without reduction with an associated reduction of mandibular movement due to a physical obstruction.

Occlusal splint. A removable artificial device affecting the relationship of the mandible to the maxilla used for diagnosis or therapy. It may be used for occlusal stabilisation, for treatment of TMD or to prevent wear of the dentition.

Osteoarthrosis. Chronic degenerative and destructive disease of the joint components and disc causing bony spurs, erosion, crepitus, pain, stiffness, limitation of movement and changes in bone morphology.

Posterior bilaminar zone. The elasticated, highly innervated and vascularised mass of retro-discal connective tissue attached to the posterior edge of the intra-articular disc and, via a more fibrous attachment, to the distal aspect of the condyle.

Soft bite guard. A resilient device made to no particular occlusion covering usually the mandibular teeth for the purpose of preventing trauma to the dentition.

Somatisation. The expression of psychological distress in an idiom of bodily complaints.

Stabilisation splint. A hard acrylic removable appliance designed, fitted and balanced to provide the features of an ideal occlusion.

Temporomandibular disorders. A collection of conditions producing abnormal, incomplete or impaired function of the TMJ(s) and articulatory system.

1. Davies S J, Gray R J M. The examination and recording of the occlusion: why and how. Br Dent J 2001; 191: 291-296, 299-302.

2. DeLong $R, K_{0} C_{1}$ Anderson $G$ C, Hodges J, Douglas W. Comparison maximum intercuspal contact of virtual dental patients and mounted dental casts. J Prosthet Dent 2002; 88: 622-630.

3. Gazit E, Fitzig S, Lieberman M A. Reproducibility of occlusal marking techniques. J Prosthet Dent 1986; 55: 505-509.

4. Kydd W, Bingham V. Quantifying contact areas in human dentition. Dent Prog 1962: 2: 288-293.

5. Davies S J, Gray R J, Al-Ani M Z, Sloan P, Worthington $\mathrm{H}$. Inter- and intra-operator reliability of the recording of occlusal contacts using 'occlusal sketch' acetate technique. Br Dent J 2002; 193: 397-400.

6. Garcia Cartagena A, Gonzalez Sequeros O, Garrido Garcia V C. Analysis of two methods for occlusal contact registration with the T-Scan system. J Oral Rehabil 1997; 24: 426-432.

7. Garrido Garcia V C, Garcia Cartagena A, Gonzalez Sequeros 0 . Evaluation of occlusal contacts in maximum intercuspation using the T-Scan system. J Oral Rehabil 1997; 24: 899-903.

8. Reza Moini M, Neff P A. Reproducibility of occlusal contacts utilizing a computerized instrument. Quintessence Int 1991; 22: 357-360.

9. Gray R J, Davies S J, Quayle A A. A clinical approach to temporomandibular disorders. 5. A clinical approach to treatment. Br Dent J 1994; 177: 101-106.

10. Okeson J P. Current terminology and diagnostic classification schemes. Oral Surg Oral Med Oral Pathol Oral Radiol Endod 1997; 83: 61-64.

11. Dworkin S, LeResche L. Research diagnostic criteria for temporomandibular disorders. J Craniomandib Disord 1992; 6: 301-334.

12. Ogus J D, Toller P A. Common disorders of the temporomandibular joint. Dental practitioners' handbook. John Wright and Sons Ltd, 1981.

13. Wright E. Manual of temporomandibular disorders. Blackwell, 2005.

14. Al-Ani Z, Davies S, Sloan P, Gray R. Change in the number of occlusal contacts following splint therapy in patients with a temporomandibular disorder (TMD). Eur J Prosthodont Restor Dent 2008; 16: $98-103$

15. Bakke M, Michler L. Temporalis and masseter muscle activity in patients with anterior open bite and craniomandibular disorders. Scand J Dent Res 1991 99: 219-228

16. Wilding R J, Owen C P. The prevalence of temporomandibular joint dysfunction in edentulous nondenture wearing individuals. J Oral Rehabil 1987; 14: 175-182.

17. De Laat A, van Steenberghe D, Lesaffre E. Occlusal relationships and temporomandibular joint dysfunction. Part II: correlations between occlusal and articular parameters and symptoms of TMJ dysfunction by means of stepwise logistic regression. J Prosthet Dent 1986; 55: 116-121.

18. Manns A, Miralles R, Cumsille F. Influence of vertical dimension on masseter muscle electromyographic activity in patients with mandibular dysfunction. $J$ Prosthet Dent 1985; 53: 243-247.

19. Ismail $Y H$, Washabaugh $R$ W. Establishing occlusal vertical dimension in edentulous patients. Pa Dent J (Harrisb) 1967; 34: 109-113.

20. Dervis E. Changes in temporomandibular disorders after treatment with new complete dentures. J Oral Rehabil 2004; 31: 320-326.

21. Gray R J, McCord J F, Murtaza G, Siddique M. The incidence of temporomandibular disorder signs in patients wearing complete dentures compared to patients with a natural dentition. Eur J Prosthodont Restor Dent 1997: 5: 99-103.

22. Kanno T, Carlsson G E. A review of the shortened dental arch concept focusing on the work by the Kayser/Nijmegen group. J Oral Rehabil 2006; 33: 850-862.

23. Mclntyre F. Restoring esthetics and anterior guidance in worn anterior teeth. A conservative multidisciplinary approach. J Am Dent Assoc 2000; 131: 1279-1283.

24. Dawson P E. Evaluation diagnosis and treatment of occlusal problems. 2nd ed. USA: The CV Mosby Company, 1989

25. Machen D E. Legal aspects of orthodontic practice: risk management concepts. Disposing of your orthodontic practice: be careful. Am J Orthod Dentofacial Orthop 1991; 99: 486-487.

26. Machen D E. Legal aspects of orthodontic practice: risk management concepts. The diagnostic dilemma. Am J Orthod Dentofacial Orthop 1991; 99: 381-332.

27. Reynders R M. Orthodontics and temporomandibular disorders: a review of the literature (1966-1988). Am J Orthod Dentofacial Orthop 1990; 97: 463-471.

28. McNamara J A Jr, Seligman D A, Okeson J P. Occlusion, orthodontic treatment, and temporomandibular disorders: a review. J Orofac Pain 1995; 9: 73-90.

29. Mew JR C. The aetiology of temporomandibular disorders: a philosophical overview. Eur J Orthod 1997; 19: 249-258.

30. Kim M R, Graber T M, Viana M A. Orthodontics and temporomandibular disorder: a meta-analysis. Am J
Orthod Dentofacial Orthop 2002; 121: 438-446.

31. Clark J R, Evans R D. Functional occlusal relationships in a group of post-orthodontic patients: preliminary findings. Eur J Orthod 1998; 20: 103-110.

32. McNamara J A Jr. Orthodontic treatment and temporomandibular disorders. Oral Surg Oral Med Oral Pathol Oral Radiol Endod 1997; 83: 107-117.

33. Eliasson S, Isacsson G. Radiographic signs of temporomandibular disorders to predict outcome of treatment J Craniomandib Disord 1992; 6: 281-287.

34. The lonising Radiation (Medical Exposure) Regulations 2000. Statutory Instrument 2000 No. 1059. London: The Stationery Office, 2000. http:// www.e-radiography.net/regsetc/lonising $\% 20$ Radiation\%20Medical\%20Exposure\%20Regs\%20 2000.htm

35. Gray R J M, Quayle A A, Horner K, Al-Gorashi A J. The effects of positioning variations in transcranial radiographs of the temporomandibular joint: a laboratory study. Br J Oral Maxillofac Surg 1991; 29: 241-249.

36. Tsukiyama Y, Baba K, Clark G T. An evidence-based assessment of occlusal adjustment as a treatment for temporomandibular disorders. J Prosthet Dent 2001; 86: 57-66

37. Koh H, Robinson P G. Occlusal adjustment for treating and preventing temporomandibular joint disorders. Cochrane Database Syst Rev 2003; CD003812.

38. Bales J, Epstein J. The role of malocclusion and orthodontics in temporomandibular disorders. J Can Dent Assoc 1994; 60: 899-905.

39. Bush F M. Malocclusion, masticatory muscle, and temporomandibular joint tenderness. J Dent Res 1985; 64: 129-133.

40. Egermark-Eriksson I, Carlsson G E, Magnusson T, Thilander B. A longtudinal study on malocclusion in relation to signs and symptoms of cranio-mandibular disorders in children and adolescents. Eur J Orthod 1990; 12: 399-407.

41. Pullinger A G, Seligman D A, Gornbein J A. A multiple logistic regression analysis of the risk and relative odds of temporomandibular disorders as a function of common occlusal features. J Dent Res 1993: 72: 968-979.

42. Pullinger A G, Srligman D A. Quantification and validation of predictive values of occlusal variables in temporomandibular disorders using a multifactorial analysis. J Prosthet Dent 2000; 83: 66-75.

43. Juniper R P. Temporomandibular joint dysfunction: a theory based upon electromyographic studies of the lateral pterygoid muscle. Br J Oral Maxillofac Surg 1984; 22: 1-8.

44. Conti P C, Ferreira P M, Pegoraro L F, Conti J V Salvador M C. A cross-sectional study of prevalence and etiology of signs and symptoms of temporomandibular disorders in high school and university students. J Orofac Pain 1996; 10: 254-262.

45. Clark G, Tsukiyama Y, Baba K, Simmons M. The validity and utility of disease detection methods and occlusal therapy for temporomandibular disorders. Oral Surg Oral Med Oral Pathol Oral Radiol Endod 1997; 83: 101-106.

46. De Boever J A, Carlsson G E, Klineberg L J. Need for occlusal therapy and prosthodontic treatment in the management of temporomandibular disorders. Part I. Occlusal interferences and occlusal adjustment. J Oral Rehabil 2000; 27: 376-379.

47. Okeson J P. Occlusion and functional disorders of the masticatory system. Dent Clin North Am 1995; 39: 285-300.

48. McNeill C. Science and practice of occlusion. Hong Kong: Quintessence Publishing Co, 1997.

49. Yatani H, Hatanaka K, Matsuka Y, Minakuchi H, Tomonari T. Multivariate analysis of risk factors in relation to TMD symptoms. J Oral Rehabil 2002; 29: 883.

50. Ash M M, Ramfjord S P. Occlusion. 4th ed. Philadelphia: WB Saunders Company, 1995.

51. Klineberg I, Jagger R. Occlusion and clinical practice: an evidence-based approach. London: Wright, 2004

52. Weyant $R \mathrm{~J}$. Questional benefit from occlusal adjustment for TMD disorders. J Evid Based Dent Pract 2006; 6: 167-168.

53. Fricton J. Current evidence providing clarity in management of temporomandibular disorders: 
summary of a systematic review of randomized clinical trials for intra-oral appliances and occlusal therapies. J Evid Based Dent Pract 2006: 6: 48-52.

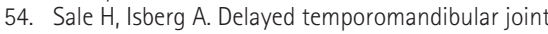
pain and dysfunction induced by whiplash trauma: a controlled prospective study. J Am Dent Assoc 2007; 138: 1084-1091.

55. Gola R, Richard O, Guyot L, Cheynet F. [Whiplash lesions and temporomandibular joint disorders]. Rev Stomatol Chir Maxillofac 2004; 105: 274-282.

56. Boniver R. Temporomandibular joint dysfunction in whiplash injuries: association with tinnitus and vertigo. Int Tinnitus J 2002; 8: 129-131.

57. Classification and diagnostic criteria for headache disorders, cranial neuralgias and facial pain. Cephalalgia 1988; 8(Suppl 7): 1-96.

58. Lele S, Hooper L. Pharmacological interventions for pain in patients with temporomandibular disorders (TMD). (Protocol) Cochrane Database Syst Rev 2004; CD004715.

59. Carraro J J, Caffesse R G. Effect of occlusal splints on TMJ symptomatology. J Prosthet Dent 1978; 40: $563-566$.

60. Clark G T. A critical evaluation of orthopedic interocclusal appliance therapy. Design, theory, and overall effectiveness. J Am Dent Assoc 1984;
108: 359-365.

61. Kurita H, Kurashina K, Kotani A. Clinical effect of full coverage occlusal splint therapy for specific temporomandibular disorder conditions and symptoms. J Prosthet Dent 1997; 78: 506-510.

62. Davies S J, Gray R J M. The pattern of splint usage in the management of two common temporomandibular disorders. Part III: long-term follow-up in an assessment of splint therapy in the management of disc displacement with reduction and pain dysfunction syndrome. Br Dent J 1997; 183: 279-283.

63. Clark G T. Treatment of jaw clicking with temporomandibular repositioning: analysis of 25 cases. Cranio 1984; 2: 263-270.

64. Clark G T. The TMJ repositioning appliance: a technique for construction, insertion, and adjustment. Cranio 1986; 4: 37-46.

65. Davies S J, Gray R J M. The pattern of splint usage in the management of two common temporomandibular disorders. Part I: The anterior repositioning splint in the treatment of disc displacement with reduction. Br Dent J 1997; 183: 199-203.

66. Lundh $H$, Westesson P, Kopp S, Tillström B. Anterior repositioning splint in the treatment of temporomandibular joints with reciprocal clicking: comparison with a flat occlusal splint and an untreated control group. Oral Surg Oral Med Oral Pathol 1985; 60: 131-136.

67. Gray R J M, Davies S J, Quayle A A. A comparison of two splints in the treatment of TMJ pain dysfunction syndrome. Can occlusal analysis be used to predict success of splint therapy? Br Dent J 1991; 170: 55-58.

68. Karl P J, Foley T F. The use of a deprogramming appliance to obtain centric relation records. Angle Orthod 1999; 69: 117-124, 124-125.

69. Rose E C, Germann M, Sorichter S, Jonas I E. Case control study in the treatment of obstructive sleepdisordered breathing with an intraoral protrusive appliance. J Orofac Orthop 2004; 65: 489-500.

70. Gale D J, Sawyer R H, Woodcock A et al. Do oral appliances enlarge the airway in patients with obstructive sleep apnoea? A prospective computerized tomographic study. Eur J Orthod 2000; 22: 159-168.

71. Gray R J, Davies S J. Occlusal splints and temporomandibular disorders: why, when, how? Dent Update 2001; 28: 194-199.

72. Poyser N J, Porter R W, Briggs P F, Chana H S, Kelleher M G. The Dahl Concept: past, present and future. Br Dent J 2005; 198: 669-676.

73. The glossary of prosthodontic terms. J Prosthet Dent 2005; 94: 10-92. 